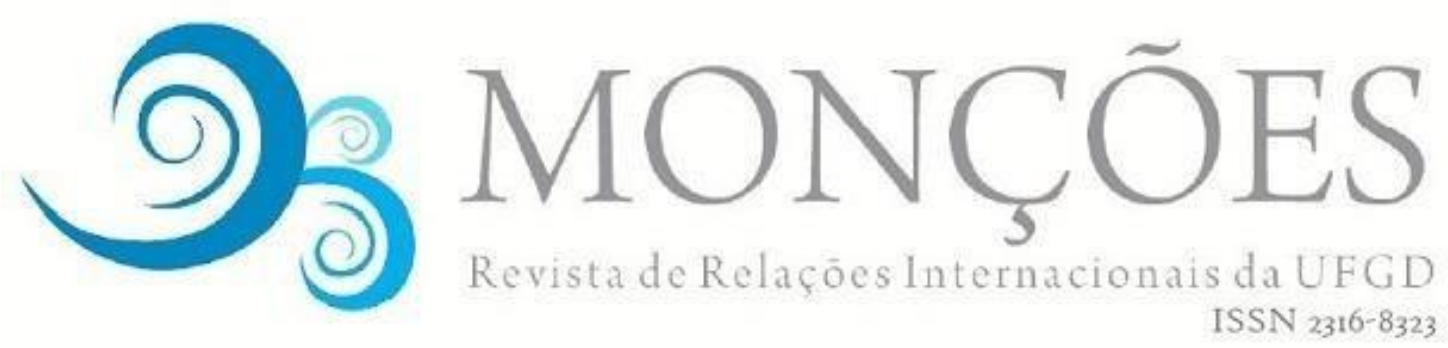

\title{
INTEGRAÇÃO REGIONAL COMO POLÍTICA PÚBLICA PARA A AMÉRICA DO SUL: UMA ANÁLISE À LUZ DA FAIXA DE FRONTEIRA BRASILEIRA
}

THAUAN SANTOS

Instituto de Relações Internacionais da Pontifícia Universidade Católica do Rio de Janeiro (IR/PUC-Rio) e Conselho Latino-Americano de Ciências Sociais (CLACSO)

\begin{abstract}
RESUMO: O presente trabalho tem como principal objetivo propor que a integração regional seja conduzida como uma política pública, levando-se em conta a região sul-americana e dando especial destaque para o papel da paradiplomacia. A justificativa reside na oscilação desse processo, que, sobretudo após a década de 1990, depende ora da conjuntura doméstica dos países, ora das influências externas. Será feita uma análise das políticas públicas voltadas para o aprofundamento da integração regional, particularmente focada na perspectiva do Brasil, evidenciando sua estreita relação com a política externa brasileira (PEB). Para tal, levar-se-á em conta as políticas públicas da Comissão Permanente para o Desenvolvimento e a Integração da Faixa de Fronteira (CDIF), da Secretaria de Desenvolvimento Regional do Ministério de Integração Nacional. Destaca-se a necessidade de avaliar a região de fronteira uma vez que ela é direta e indiretamente afetadas pelas interações transfronteiriças, com o próprio país (governos municipal, estadual e federal) e com os países vizinhos (paradiplomacia).
\end{abstract}

PALAVRAS-CHAVE: Integração Regional; Política Externa Brasileira; Faixa de Fronteira

\section{REGIONAL INTEGRATION AS PUBLIC POLICY FOR SOUTH AMERICA: AN ANALYSIS IN THE LIGHT OF THE BRAZILIAN BORDER STRIP}

\begin{abstract}
The main objective of this paper is to propose the conduct of the regional integration as a public policy, taking into account the South American region and giving particular emphasis on the role of paradiplomacy. The justification lies in the oscillation of this process that sometimes depends on the domestic context of countries, sometimes on the external influences - especially after the 1990s. We will analyze public policies aimed at deepening regional integration, particularly focused on the perspective of Brazil, pointing its close relationship with the Brazilian foreign policy (PEB). For such, the public policies of the Permanent Commission for the Development and Integration of the Border Strip (CDIF) of the Secretariat of Regional Development of the Ministry of National Integration will be taken into account. It highlights the need to evaluate the border region since it is directly and indirectly affected by cross-border interactions, with the country itself (municipal, state and federal governments) and with the neighboring countries (paradiplomacy).
\end{abstract}

KEYWORDS: Regional Integration; Brazilian Foreign Policy; Border Strip 


\section{Introdução}

Desafiando a ontologia e a epistemologia mainstream das Relações Internacionais, os processos de integração regional constituem alternativas às abordagens estadocêntricas e, por sua vez, estreitam o diálogo entre os níveis doméstico (nós) e o internacional (outros). De modo semelhante, a Política Externa dos países também constitui esse elo de ligação entre o nós e o outros, possibilitando a implementação de políticas públicas que considere o nosotros.

Embora essa discussão não faça sentido para muitos cidadãos, ela é particularmente presente na vida daqueles que vivem em regiões de fronteiras entre países. Nessas regiões, as relações sociais, econômicas e mesmo políticas transbordam os limites físicos da fronteira, o que exige especial atenção por parte dos Estados dos dois lados da mesma.

No contexto sul-americano, destaca-se o papel do Brasil nessa discussão, dado que o país possui fronteira com praticamente todos os demais países da região (BORGES, 2012). Portanto, e considerando sua assimetria em termos físicos e econômicos, frequentemente atribui-se ao país o dever de promover a integração da região. ${ }^{1}$ Contudo, é importante destacar que há diversas críticas e descrenças com relação ao perfil paymaster do Brasil nesse processo (KRAPOHL, MEISSNER; MUNTSCHICK, 2014; SOARES DE LIMA; HIRST, 2006; MATTLI, 1999).

Dessa forma, a política externa brasileira (PEB) pode representar um instrumento promotor desse papel do Brasil. No entanto, entende-se que a mesma é complexa e conta com uma diversidade de atores e instituições envolvida nas decisões, o que nos afasta da ideia de que "a presença de lideranças carismáticas ou o monopólio de uma agência possa per se explicar a definição dos interesses do país no plano internacional" (MILANI; PINHEIRO, 2013, p.11), especialmente para a região sul-americana.

\footnotetext{
${ }^{1}$ Destaca-se que na região de faixa de fronteira brasileira existe forte "a demanda por serviços públicos do país vizinho por parte de residentes na faixa de fronteira (saúde, educação, etc)." (PENHA, DESIDERÁ NETO, MORAES, 2017, p.9).
} 
O presente trabalho, portanto, fará uma inter-relação entre os conceitos de integração regional, política externa brasileira e política pública ${ }^{2}$, levando em consideração a região da faixa de fronteira do Brasil. Sendo assim, destaca-se o papel das entidades subnacionais, seja no escopo nacional, seja no âmbito internacional (regional). Analisa-se, assim, a Comissão Permanente para o Desenvolvimento e a Integração da Faixa de Fronteira (CDIF), da Secretaria de Desenvolvimento Regional do Ministério de Integração Nacional, destacando-a como um instrumento essencial para promoção da integração regional da América do Sul.

\section{Política Externa e Integração Regional}

Existe grande dificuldade de se encontrar uma definição clara e coesa de "integração regional", pois se trata de um conceito que depende do contexto histórico, social e temporal, bem como da abordagem teórica e da disciplina que o analisa. Portanto, a existência dessas diferenças traz grande dificuldade para a compreensão desse fenômeno (RICHARD, 2014; NYE, 1968), que deve ser interpretado como um processo dinâmico.

Além disso, é importante refletirmos sobre as seguintes questões: (i) integração por quem; (ii) para quem; e (iii) contra quem? (HVEEM, 1974). Nesse sentido, percebe-se a complexidade da questão, que é frequentemente confundida com cooperação internacional e/ou acordos preferenciais de comércio (PTAs). Para fins desse trabalho, defende-se que integração regional seja "um processo multifacetado por meio do qual se busca a promoção de políticas comuns e conjuntas em uma dada região com vistas à redução das assimetrias e desigualdades da/na região, bem como à promoção do bem-estar socioeconômico" (SANTOS; DINIZ JÚNIOR, 2017, p. 2).

Dessa forma, e conforme a definição supracitada, trata-se de um processo normativo, que pode decorrer de práticas informais cotidianas entre as partes

\footnotetext{
2 No escopo desse trabalho, entende-se por "políticas públicas" a definição de um dos "pais fundadores" da área, Lindblom $(1959,1979)$, que questiona o foco sobre o racionalis mo de até então atribuído à definição (LASWELL, 1936; SIMON, 1957). Nesse sentido, destacam-se fatores como burocracias, partidos políticos e grupos de interesse como essenciais à definição das agendas prioritárias a serem desenvolvidas, bem como a necessidade de a política pública ser sustentada (no sentido de não ser vulnerávelàs conjunturas político-econômica).
} 
envolvidas, mas que, em última instância, ganha caráter formal e institucional, traduzindo-se em políticas (regionais) comuns. Contudo, as "partes envolvidas", frequentemente associadas aos Estados, estão sujeitas a influências externas (internacionais e extra-regionais) e/ou internas (domésticas), o que pode levar à instabilidade desses processos (BLAVOUKOS; BOURANTONIS, 2014; KRAPOHL, MEISSNER; MUNTSCHICK, 2014; CARRANZA, 2003).

Diante dessa interação de variáveis internas e externas, uma consequência direta da agenda da integração regional é seu vínculo estreito e intrínseco com a agenda da política externa (PECEQUILO; CARMO, 2013; MARIANO; RAMANZINI JR., 2012; SPEKTOR, 2011; ONUKI; OLIVEIRA, 2006).

No que se refere às teorias da integração regional, sempre se destacou 0 papel das elites na condução desse processo (BRESSAN, 2015; VIGEVANI; RAMANZINI, 2011; ROSAMOND, 2000; PUTNAM, 1976; MTRANY, 1948). Dessa forma, muitos estudos acabam avaliando a relação entre eleições e partidos políticos com a evolução da política externa e da integração regional (BOITE; BERRINGER, 2014; VIGEVANI; RAMANZINI JR., 2011; AMORIM, 2010; ONUKI; OLIVEIRA, 2006).

Já com relação às teorias e às análises da política externa brasileira (PEB), sobretudo pós-1990, alguns autores passaram a destacar a pluralização de atores (MILANI; PINHEIRO, 2013; SOARES DE LIMA, 2000; CASON; POWER, 2009), enquanto outros destacavam a (re)configuração do processo decisório (PINHEIRO, 2009; SNYDER, 2005; ROSENAU, 1969). A partir desse período, a agenda da PEB ganha espaço no campo das políticas públicas (AMORIM NETO; MALAMUD, 2015), estreitando a relação entre os níveis I e II (internacional e doméstico, respectivamente) do jogo de dois níveis (PUTNAM, 1988).

Conforme já destacado, avaliar o processo de integração regional exige, necessariamente, compreender o contexto (inter)nacional. No entanto, não existe consenso na literatura acerca dos principais drivers da política externa. Focada no caso da PEB (entre os períodos FHC e Lula da Silva), Lustig (2016, p. 121) defende que "evidence shows that changes in the discursive profile of a foreign policy do not depend on domestic conditions, or at least do not depend on the party affiliation or ideology of whoever is in power, but seem to respond to 
systemic issues". Sendo assim, argumenta que houve continuidade da PEB entre os períodos em questão (PECEQUILO, 2008; COSTA VAZ, 2004; CERVO, 2002).

Outros autores apenas defendem a existência de continuidade para o caso do MERCOSUL (MARIANO; RAMANZINI JR., 2012), destacando ora a relevância das políticas domésticas (VIGEVANI; RAMANZINI JR., 2011) ora o contexto político-econômico internacional (LUSTIG, 2016) como principais variáveis explicativas. Por sua vez, há autores que discordam integralmente do argumento, defendendo uma mudança da administração no período Lula da Silva em termos de liderança na América do Sul (SARAIVA, 2010).

Independentemente do posicionamento quanto à continuidade ou à mudança da PEB, pode-se defender que tal política para o MERCOSUL sempre prezou pela autonomia e desenvolvimento (AMORIM NETO; MALAMUD, 2015; MARIANO; RAMANZINI JR., 2012), ao mesmo tempo em que defendia o universalismo, a não-intervenção e a autodeterminação, de modo mais amplo (PECEQUILO; CARMO, 2013; VIGEVANI; RAMANZINI JR., 2011; VIGEVANI et al., 2008). Essa autonomia está alinhada à lógica intergovernamental do MERCOSUL, o que leva à reflexão acerca do arcabouço institucional do bloco regional (CAMARGO, 2006).

Embora não esteja no contexto dessa pesquisa detalhar a conjuntura na qual se deu a formação do MERCOSUL, cabe destacar a existência de eventos prévios à assinatura do Tratado de Assunção (1991). Entre as décadas de 1940 e 1960, houve iniciativas pontuais, porém malsucedidas (BUENO, VIGEVANI e RAMANZINI JR., 2011). Destaca-se, contudo, os projetos em infraestrutura hidrelétrica binacional de Itaipu (Brasil-Paraguai) e Corpus (Brasil-Argentina) (ESPÓSITO NETO, 2013). Nos anos 2000, o foco de até então sobre a integração da América Latina é substituído pela nova concepção regional de América do Sul (MALAMUD, 2011).

No contexto da primeira década do século XXI da América do Sul, precisamente nos países do MERCOSUL, destaca-se o protagonismo dos governos de esquerda. De fato, associa-se essa mudança regional à promoção do regionalismo sul-americano (VIGEVANI; RAMANZINI JR., 2011), porém é importante destacar que tais governos tendem a ser menos propensos à cessão 
de soberania a instâncias supranacionais (VIGEVANI, 2012; ONUKI; OLIVEIRA, 2006).

Embora o posicionamento do Brasil em relação à integração do Cone Sul fosse e seja relacionado a um interesse real na integração, tal interesse não era separado do objetivo de assegurar melhores condições de participação em outras arenas internacionais, como fóruns econômicos e políticos regionais e multilaterais (VIGEVANI; RAMANZINI JR., 2011). É curioso perceber, nesse sentido, uma relação estreita com o conceito cepalino de "regionalismo aberto" (CARRANZA, 2003) característico dos anos 1990.

Apesar desses objetivos simultâneos, fica bastante evidente para muitos autores que a prioridade da política externa brasileira no período Lula da Silva era a integração sul-americana (BOITO; BERRINGER, 2014; AMORIM, 2010). Além disso, apesar da crítica sobre a crise e lentidão do MERCOSUL (VIGEVANI, 2012; CAMARGO, 2006), em particular devido à não coordenação das políticas macroeconômicas (CARRANZA, 2003), cabe destacar o seu avanço na questão política, com o Protocolo de Ushuaia (1998), com o Parlasul e com o Fundo para Convergência Estrutural do MERCOSUL (FOCEM) elementos que podem indicar uma mudança relativa da questão institucional (MARIANO; RAMANZINI JR., 2012). Vale mencionar, ainda, a relação com a Comunidade Andina de Nações (CAN), além da própria criação da Iniciativa para a Integração da Infraestrutura Regional Sul-Americana (IIRSA) ${ }^{3}$ e da União SulAmericana de Nações (UNASUL).

The integration of South America involved not only innumerable rounds of negotiation by Ministers and/or high-level officials, but also the personal participation of the President himself. In a little more than eight months in office, President Lula had received, at least once, every South American Head of State. In two years, he visited all countries of the region. Needless to say: nothing remotely similar had happened before (AMORIM, 2010, p. 229).

Fica claro, portanto, que o Brasil tem desempenhado um papel fundamental no sentido de promover a integração regional, sobretudo do ponto

\footnotetext{
3 Para Borges (2012), a IIRSA constitui um instrumento para a consolidação da liderança brasileira na região. Honório (2013) argumenta que o Brasil possuiuma atuação paradoxal na América do Sul por meio da IIRSA, dado o "descompasso" entre o discurso diplomático de fortalecimento da integração e a atuação brasileira. "No entanto, se no discurs o diplomático de Lula a IIRSA vai desaparecendo ao longo dos anos o tema da infraestrutura ganhou relevância regional e nacional durante seu governo, em detrimento do avanço institucional da iniciativa" (Ibid., p. 197).
} 
de vista de sua política externa recente. Embora nesses 25 anos de MERCOSUL o comportamento dos Estados membros seja frequentemente associado a movimentos de aproximação e distanciamento, a análise da política externa (APE) brasileira tem sido utilizada por diversos acadêmicos para compreender esses movimentos, dando particular atenção à figura dos presidentes e de seus partidos.

\section{Integração Regional e Faixa de Fronteira}

Conforme se destacou na seção anterior, as políticas para integração regional do MERCOSUL são muito vulneráveis à conjuntura nacional e aos eventos externos à própria região. Essa particularidade dificulta a consolidação de políticas regionais, uma vez que as prioridades mudam com frequência - 0 que ameaça o projeto e o processo de integração em si.

Apesar disso, e mantendo o foco da análise sobre a perspectiva brasileira,

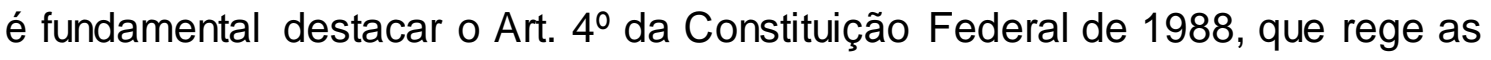
relações internacionais do Brasil, que, em seu Parágrafo único, afirma: "A República Federativa do Brasil buscará a integração econômica, política, social e cultural dos povos da América Latina, visando à formação de uma comunidade latino-americana de nações".

Portanto, é importante demarcar o compromisso legal do Brasil para com a integração regional, ainda que, conforme já destacado, o foco tenha passado a ser a América do Sul. Contudo, há algumas críticas com relação ao papel do Brasil na região, destacando que "while its regional leadership has grown on paper, in practice it has met growing resistance" (MALAMUD, 2011, p. 19).

Nesse contexto, e especificamente com relação à PEB dos governos Lula da Silva (2003-2010), criticou-se a agenda, afirmando que ela estava muito politizada $^{4}$, seja para a integração regional, seja para a cooperação sul-sul (CSS) - sobretudo com países da África. Diante desse argumento, é importante refletir sobre o questionamento de Carranza (2014, p. 163): "is the politicization of integration issues an indicator of resilience or decline?".

\footnotetext{
${ }^{4}$ Cabe destacar, contudo, o seguinte fragmento: “[...] o desenvolvimento do processo de integração tem uma dimensão política crescente, a qual requer ações coordenadas e sistematizadas de todos os atores nele envolvidos" (MERCOSUL, 2004)
} 
Dita "politização", na realidade, evidencia(va) que a integração regional se afastava de seu tradicional perfil econômico e visava a alcançar objetivos políticos (DABÈNE, 2009), como a consolidação da democracia e dos direitos humanos na região. É fato, porém, que, no contexto regional do século $\mathrm{XXI}$, também havia diferentes iniciativas como a CAN, a IIRSA e a UNASUL, o que desafiava a construção de consensos regionais (BORGES, 2012).

Dessa forma, destacaremos as políticas públicas brasileira de promoção da integração regional com os demais países da América do Sul. Cabe destacar, contudo, que diferentemente do que se faz recorrentemente na literatura, é necessário evitar comparações entre experiências distintas, sobretudo se feita com a União Europeia (UE).

A título de exemplo, de acordo com dados do Banco Mundial, a superfície total da UE-28 (4,4 milhões de $\left.\mathrm{km}^{2}\right)$ representa cerca de metade da superfície do Brasil (8,5 milhões de $\mathrm{km}^{2}$ ) e menos de $25 \%$ da superfície total da América do Sul (17,8 milhões de km²). Já em termos populacionais, com base no ano de 2015, a da UE-28 (509,6 milhões), é cerca do dobro da brasileira (207,8 milhões) e aproximadamente $20 \%$ superior à da América do Sul (415 milhões).

Por isso, tal comparação é difícil de ser sustentada. Então, a presente seção levará em conta apenas as políticas públicas brasileiras para a região da América do Sul, particularmente aquelas da Comissão Permanente para o Desenvolvimento e a Integração da Faixa de Fronteira (CDIF), da Secretaria de Desenvolvimento Regional do Ministério de Integração Nacional (MI). O Art. 1ํㅜ do Decreto de 8 de setembro de 2010 institui a Comissão Permanente para o Desenvolvimento e a Integração da Faixa de Fronteira (CDIF). Já em seu Art. 2ํㅡ, defende-se que compete à CDIF:

I- definir, respeitadas as especificidades de atuação dos órgãos competentes, critérios de ação conjunta governamental para o desenvolvimento e a integração na área abrangida pela Faixa de Fronteira, estimulando a integração das políticas públicas e a parceria com os demais entes públicos visando a complementaridade das ações;

II - apresentar estudos que visem a melhoria da gestão multissetorial para as ações do Governo Federal no apoio ao desenvolvimento e à integração da área abrangida pela Faixa de Fronteira;

III - propor o desenvolvimento de sistema de informações para o gerenciamento das ações a que se refere o inciso II;

IV - apresentar planos regionalizados de desenvolvimento e integração fronteiriços; e 
V - interagir com núcleos regionais estabelecidos para debater questões de desenvolvimento e integração fronteiriços (grifos do autor).

Nesse sentido, fica evidente o papel das políticas públicas no estímulo à integração regional. Em seu Art. 3ํㅗ o Decreto defende que a CDIF seja integrada a 20 entes públicos, entre eles 18 Ministérios, a Secretaria de Relações Institucionais da Presidência da República e o Gabinete de Segurança Institucional da Presidência da República. Ainda no Art. $3^{\circ}$, nos $\S 1^{\circ}, 2^{\circ}, 3^{\circ}, 4^{\circ}$ e 5º, argumenta-se, por exemplo, em prol da participação de Municípios e do Fórum de Governadores da Amazônia Legal.

De acordo com o Instituto Brasileiro de Geografia e Estatística (IBGE), a faixa de fronteira (FF) "é a faixa interna de $150 \mathrm{~km}$ de largura, paralela à linha divisória terrestre do território nacional, considerada área indispensável à Segurança Nacional"5. Seus dispositivos regulamentares básicos são: (i) Lei no 6.634, de 02/05/796, que revoga a Lei no 2.597, de 12/09/55, e altera o DecretoLei no 1.135, de 03/12/70; e (ii) Decreto no 85.064, de 26/08/807, que regulamenta a lei supracitada. Vale destacar que criação da faixa de fronteira remonta ao século XIX, com a criação da Lei no 601, de 18/12/1850, inicialmente com 10 léguas (66 km). Com a Constituição de 1934, cria-se a "faixa de segurança nacional" e estende-se sua extensão para 150 km (PIMENTA NETO, 2014); já a Constituição de 1988, em seu Capítulo II, Art. 20, $\S 2^{\circ}$ define que "A faixa de até cento e cinquenta quilômetros de largura, ao longo das fronteiras terrestres, designada como faixa de fronteira, é considerada fundamental para defesa do território nacional, e sua ocupação e utilização serão reguladas em lei"8.

A Tabela 1 apresenta o total de municípios brasileiros da faixa de fronteira brasileira por $\operatorname{arco}^{9}$, unidade federativa (UF) e população. Percebe-se que a população da faixa de fronteira corresponde a $5,6 \%$ da população brasileira em

\footnotetext{
${ }^{5}$ Ver http://www.ibge.gov.br/home/geociencias/cartogramas/ff brasil.html.

${ }^{6}$ Ver http://www.planalto.gov.br/ccivil_03/leis/L6634.htm.

${ }^{7}$ Ver http://www.planalto.gov.br/ccivil 03/decreto/antigos/d85064.htm.

8 Ver http://www.planalto.gov.br/ccivil 03/constituicao/constituicao.htm. Para maiores informações acerca da legislação brasileira sobre a matéria "faixa de fronteira", ver http://info.lncc.br/front.html.

${ }^{9}$ As ações do Governo Federal para a Faixa de Fronteira são desenhadas a partir de três grandes arcos, definidos a partir da proposta de reestruturação do Programa de Desenvolvimento da Faixa de Fronteira (BRASIL, 2005), com base na Política Nacional de Desenvolvimento Regional (PNDR) do Ministério da Integração (MI).
} 
2010, embora ocupe cerca de 34\% do território nacional - trata-se, portanto, de uma área pouco povoada ${ }^{10}$.

Tabela 1: Total de municípios brasileiros da faixa de fronteira por arco, UF e população

\begin{tabular}{|c|l|c|c|}
\hline Arco & \multicolumn{1}{|c|}{ Unidade Federativa (UF) } & Municípios & População (2010) \\
\hline \multirow{5}{*}{ Norte } & Acre (AC) & 22 & 733.559 \\
\cline { 2 - 4 } & Amazonas (AM) & 21 & 477.538 \\
\cline { 2 - 4 } & Roraima (RR) & 15 & 450.479 \\
\cline { 2 - 4 } & Pará (PA) & 5 & 206.544 \\
\cline { 2 - 4 } & Amapá (AP) & 8 & 102.267 \\
\cline { 2 - 4 } & TOTAL & 71 & 1.970 .387 \\
\hline \multirow{5}{*}{ Central } & Mato Grosso do Sul (MS) & 44 & 1.073 .833 \\
\cline { 2 - 4 } & Mato Grosso (MT) & 28 & 479.294 \\
\cline { 2 - 4 } & Rondônia (RO) & 27 & 930.364 \\
\cline { 2 - 4 } & TOTAL & 99 & 2.483 .491 \\
\hline \multirow{5}{*}{ Sul } & Rio Grande do Sul (RS) & 197 & 3.147 .027 \\
\cline { 2 - 4 } & Paraná (PR) & 139 & 2.372 .942 \\
\cline { 2 - 4 } & Santa Catarina (SC) & 82 & 788.382 \\
\cline { 2 - 4 } & TOTAL & $\mathbf{5 8 8}$ & $\mathbf{1 0 . 3 0 8 . 3 5 1}$ \\
\hline Brasil & - & 229 \\
\hline
\end{tabular}

Fonte: Elaboração própria com base em BRASIL (2014) e IBGE (2010)

Em escala subcontinental (regional), assume-se como condicionante da ação governamental: (i) a formulação um novo marco regulatório das interações entre os Estados (particularmente do MERCOSUL e da CAN); (ii) a integração física da malha rodoviária, com objetivo de ligar o lado Atlântico ao Paćfico; (iii) a intensificação do tráfico de armas e drogas ilícitas; e (iv) a expansão de movimentos migratórios e pendulares (BRASIL, 2005).

Do ponto de vista da escala nacional, destaca-se: (i) a necessidade de adaptação das políticas públicas estatais à 'permeabilidade' das fronteiras; e (ii) a integração da Faixa de Fronteira às outras regiões do país por estar à frente do processo de integração sul-americana. É, contudo, do ponto de vista da escala subnacional e local que se precisa aperfeiçoar as políticas públicas, uma vez que existe crítica e demanda por maior conhecimento do centro decisório

${ }^{10}$ Com base em dados do Ministério de Relações Exteriores (MRE), 11\% da comunidade brasileira no exterior está próxima à fronteira com o Brasil e 68,5\% do total dos brasileiros residentes na América do Sul estão em área de fronteira (BRASIL, 2013a). 
nacional (superior) sobre as especificidades territoriais dos municípios de fronteira (inferior).

Pela análise da Figura 1, percebe-se que faixa de fronteira faz divisa com Argentina, Bolívia, Colômbia, Guiana, Guiana Francesa ${ }^{11}$, Paraguai, Peru, Suriname, Uruguai e Venezuela. Além disso, cabe mencionar que atualmente a análise da região se dá a partir da divisão dos municípios em 17 sub-regiões (BRASIL, 2005).

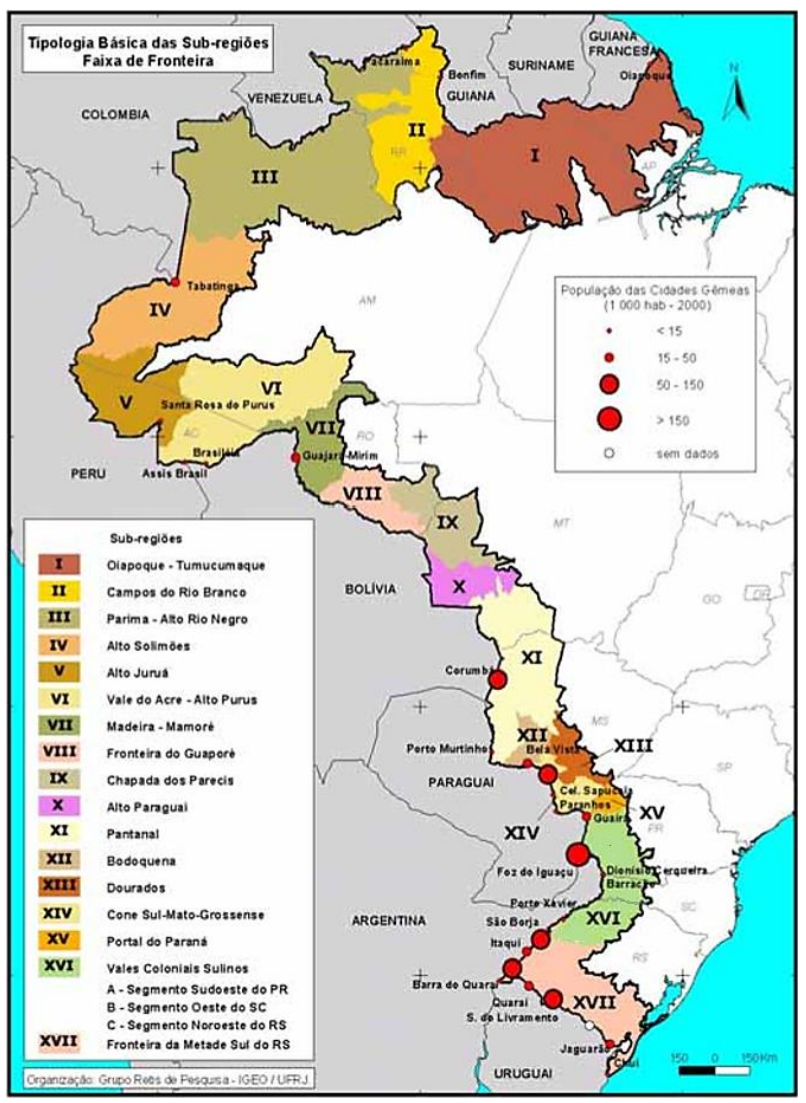

Figura 1: Faixa de fronteira brasileira por sub-regiões

Fonte: BRASIL (2005)

\section{Faixa de Fronteira e Política Públicas}

Diante dos limites das políticas estabelecidas pelo Programa de Desenvolvimento da Faixa de Fronteira (PDFF), a Secretaria de Programas Regionais (SPR) do Ministério da Integração Nacional (MI) contratou um projeto do Grupo Retis, da Universidade Federal do Rio de Janeiro (UFRJ), para subsidiar as novas orientações que seriam adotadas.

${ }^{11}$ É necessário, contudo, destacarque a Guiana Francesa é um território ultra-mar da França. 
O projeto atual [reestruturação do PDFF] nasceu de uma avaliação negativa por parte da Secretaria de Programas Regionais do Ministério da Integração Nacional (2003-2007) sobre os fundamentos e a funcionalidade do Programa Social da Faixa de Fronteira (1999-2002). Os recursos destinados ao Programa foram dispersos em uma série de pequenas obras e ações pontuais, por iniciativas do Poder Legislativo, sem diretrizes claras e sem consideração das diferenças sub-regionais da Faixa em termos de desenvolvimento econômico e cidadania fronteiriça (...) Observa-se a concentração no Acre, Roraima e Noroeste do Rio Grande do Sul, sendo que a maior parte dos convênios foi destinada a infraestrutura urbana e a um aglomerado de pequenas obras de vários tipos (BRASIL, 2005, p. 14).

É fundamental destacar as particularidades presentes na extensão nortesul da faixa de fronteira brasileira (PÊGO et al., 2017), bem como a presença de "cidades limítrofes" com países vizinhos, sendo gêmeas ${ }^{12}$ ou não ${ }^{13}$. Tais cidades são mais diretamente afetadas por questões políticas, econômicas e diplomáticas dos países envolvidos, consequentemente são muito importantes para o processo de integração regional, ao mesmo tempo em que correspondem ao principal locus de atividades ilícitas, como tráfico de drogas e produtos ilegais (BRASIL, 2016).

Destaca-se, portanto, que as unidades subnacionais (municípios e cidades da faixa de fronteira) desempenham, igualmente, um papel fundamental na cooperação descentralizada e transfronteiriça (PRADO, 2014; 2015; VIGEVANI et al., 2004). Isso dá força ao papel da paradiplomacia como forma de inserção internacional dessas unidades subnacionais (CASTELO BRANCO, 2007).

É importante fazer um breve parênteses para prover uma compreensão plena do conceito de paradiplomacia. Soldatos (1990, p. 35) a define como "a atividade de política externa de uma unidade federativa", enquanto Prado (2013, p. 65) afirma ser a "terminologia aplicada à atuação internacional dos governos subnacionais. Essa atuação pode estar concentrada em motivações políticas, culturais e econômicas". "A paradiplomacia é, antes de tudo, uma possibilidade

\footnotetext{
12 "Municípios cortados pela linha de fronteira, seja essa seca ou fluvial, articulada ou não por obra de infraestrutura, que apresentem grande potencial de integração econômica e cultural, podendo ou não apresentar uma conurbação ou semi-conurbação com uma localidade do país vizinho, assim como manifestações "condensadas" dos problemas característicos da fronteira, que aí adquirem maior densidade, com efeitos diretos sobre o desenvolvimento regional e a cidadania" (BRASIL, 2014, p. 45). Também conhecidas por "localidades fronteiriças vinculadas", há 29 cidades gêmeas no Brasil.

13 "Apresent[a]m, individualmente, população inferior a 2.000 (dois mil) habitantes" (Idem, p. 45).
} 
que os governos subnacionais têm de buscar parcerias para o seu desenvolvimento, sem depender exclusivamente da ação dos seus respectivos governos centrais" (lbid., p. 66).

Nessa região, o planejamento e a execução das políticas não dependem apenas dos esforços nacionais, dessa forma é comum a elaboração de acordos bilaterais e/ou multilaterais - inter-relação da vertente internacional do PDFF com o Ministério de Relações Exteriores (MRE), por intermédio da PEB (BRASIL, $2009)^{14}$. Dada a diversidade de países vizinhos na FF, uma política que pode ser implementada é "a criação de Comitês de Fronteira (CF) binacionais, bem como a reativação e o fortalecimento daqueles já existentes, podem representar uma ferramenta significativa para a otimização da infraestrutura existente (Ibid., p. 20).

No que se refere à questão da infraestrutura, vale destacar que ela é carente, uma vez que essa região é historicamente afastada dos principais centros dinâmicos da economia brasileira. Nesse sentido, é interessante articular essas demandas locais e majoritariamente binacionais com os projetos da IIRSA, desenvolvendo projetos de integração física e produtiva, de modo a facilitar o comércio, a circulação de pessoas e a gestão integrada dos recursos naturais (BRASIL, 2013a). Sendo assim, é possível promover o desenvolvimento regional e a integração da América do Sul levando-se em consideração o bemestar da população fronteiriça aliada ao desenvolvimento produtivo local.

É primordial considerar também que as regiões dessa fronteira (arcos) não são homogêneas. O Arco Norte, por exemplo, possui povoamento escasso, difícil acesso, bioma amazônico e extensas áreas de reservas ambientais e/ou indígenas. O Arco Sul, por sua vez, é mais povoado, apresenta condições topográficas de mais fácil acesso, assim como é caracterizado por intenso fluxo de pessoas e mercadorias. Dessa forma, cada arco possui necessidades específicas quando se trata de políticas públicas integradoras. Sendo assim, e com base em BRASIL (2013a), segue principais políticas brasileiras com seus países vizinhos.

\footnotetext{
${ }^{14}$ Contudo, a política externa integracionista nes sa região de fronteira pode ser comp reendida apenas como uma política de reconhecimento da experiência da integração já existente (BENTO, 2015).
} 
Com a Argentina, vale destacar a instalação da Comissão de Cooperação e Desenvolvimento Fronteiriço (CODEFRO), em 2012, que constitui a mais alta instância bilateral para tratar de temas fronteiriços. Cabe mencionar, ainda, os Comitês de Integração Fronteiriça ${ }^{15}$, que têm se reunido com frequência e levado em consideração as demandas das comunidades locais. Além disso, no que se refere à infraestrutura, lançou-se em 2010 uma licitação internacional para contratação de estudo de otimização da conexão entre os países.

Há 3 Comitês de Fronteira Brasil-Paraguaii" ${ }^{16}$ embora as reuniões não venham ocorrendo com assiduidade. Além disso, criou-se em 2009 o Regime de Tributação Unificada (RTU), que visa a facilitar a formalização da atividade dos pequenos importadores que atuam na Ponte da Amizade - contudo, na prática, existem problemas para seu pleno funcionamento.

Já no Uruguai, vale destacar o papel dos Comitês de Fronteira BrasilUruguai, além da nova ponte sobre o Rio Jaguarão, que visa a melhorar o tráfego rodoviário do transporte internacional de cargas e passageiros entre os países da região. Destaca-se o "Ajuste Complementar ao Acordo para Prestação de Serviços de Saúde" nas cidades fronteiriças entre Brasil-Uruguai, de 2008 (Decreto o 7.239/10), que proporciona acesso recíproco de cidadãos de ambos os países a serviços de saúde nos dois lados da fronteira (localidades fronteiriças vinculadas) e evita grandes deslocamentos de pacientes dentro da região. $O$ Decreto n. ${ }^{\circ}$ 8.455/15 "promulga o Acordo entre os dois governos para a Criação de Escolas e/ou Institutos Binacionais Fronteiriços Profissionais e/ou Técnicos e para o Credenciamento de Cursos Técnicos Binacionais Fronteiriços" (BÜHRING, 2015, p. 230).

Por sua vez, a Comissão de Vizinhança e Integração Brasil-Colômbia constitui o principal foro de discussão dos temas de fronteira entre os países e foi criada em 1993. Há discussões e acordos que visam a facilitar o comércio entre as cidades de Tabatinga e Letícia. Vale destacar que o Brasil assinou

\footnotetext{
15 Uruguaiana-Paso de Los Libres, Foz do Iguaçu-Puerto Iguazú e Barracão/Dionísio Cerqueira-Bernardo de Irigoyen.

16 Ciudad del Este-Foz do Iguaçu; Salto del Guairá-Guaíra-Mundo Novo; e Pedro Juan Caballero-Ponta Porã.
} 
Acordos para Permissão de Residência, Estudo e Trabalho aos Nacionais Fronteiriços, com Uruguai (2002) e Colômbia (2010).

Já na Venezuela, o Grupo de Trabalho (GT) sobre Desenvolvimento Fronteiriço aborda temas como meio ambiente, educação, saúde e assuntos indígenas. Em 2010, firmou-se o Acordo sobre Localidades Fronteiriças Vinculadas ${ }^{17}$, que define 0 direito de residência e estudo dos dois lados da fronteira, e assinou-se o Acordo para o Estabelecimento de Regime Especial Fronteiriço entre as Localidades Fronteiriças Vinculadas.

Já com a Bolívia, assinou-se em 2011 um acordo que substitui os antigos "Comitês de Fronteira" pelos "Comitês de Integração Fronteiriça"18 e realizou-se em 2013 o Primeiro Encontro Fronteiriço Brasil-Bolívia de Autoridades de Segurança Pública. Relativamente à infraestrutura, destacam-se os projetos de pontes binacionais no Rio Mamoré $(\mathrm{RO})$ e lgarapé Rapirrã ( $A C)$.

Em 2009, criou-se o Comitê de Fronteira Brasil-Guiana, que busca avaliar mecanismos de cooperação em diversas áreas, como meio ambiente, educação, vigilância sanitária e circulação de pessoas. Em matéria de infraestrutura, inaugurou-se no mesmo ano uma ponte sobre o Rio Tacutu ligando os dois países, bem como um regime especial fronteiriço e de transporte para as cidades de Bonfim e Lethem.

No Peru, criou-se em 2010 a Comissão Vice Ministerial de Integração Fronteiriça (CVIF) e a Rodovia Interoceânica. Contudo, vale destacar que não existe um comitê específico para tratar da integração fronteiriça Brasil-Suriname, apesar do Acordo de Regularização Migratória firmado entre os países em 2004.

De modo geral, e no que se refere à educação, é fundamental destacar o Projeto Escola Intercultural Bilíngue de Fronteira (PEIBF), que é desenvolvido em escolas de fronteira com países do MERCOSUL (Argentina, Paraguai, Uruguai e Venezuela). Tal projeto começou bilateralmente com Brasil-Argentina, em 2005, e propõe transformá-las em instituições interculturais bilíngues capazes de oferecer: (i) aos alunos: formação baseada no conceito de fronteira ligado à integração regional, ao conhecimento e respeito pela cultura e às

\footnotetext{
${ }_{17}^{17}$ Pacaraima e Santa Elena do Uairén.

${ }^{18}$ Brasiléia-Epitaciolândia/Cobija, Guajará-Mirim/Guayaramerín, Corumbá/Puerto Suárez e Cáceres/San Matias.
} 
produções do país vizinho; e (ii) aos professores: intercâmbio entre os países participantes.

O Brasil também tem buscado construir políticas específicas à faixa de fronteira, com destaque para o diálogo federativo com os núcleos regionais de fronteira no âmbito da Comissão Permanente para Integração e Desenvolvimento da Faixa de Fronteira (CDIFF) e para a Estratégia Nacional de Segurança Pública nas Fronteiras (ENAFRON) (BRASIL, 2013).

É importante considerar que, no âmbito do MERCOSUL:

O Foro Consultivo de Municípios, Estados-membros, Províncias e Departamentos (FCCR) se posiciona como um importante espaço para as unidades subnacionais do Mercado Comum do Sul. A partir da criação do foro, foi possível estimular a articulação de seus membros, aumentando a participação quantitativa e qualitativamente nos temas relacionados ao processo de integração, trazendo as questões locais e as expectativas dos governos subnacionais para a agenda decisória do processo de integração (PRADO, 2014, p. 119).

Vale destacar, ainda, o papel da Comissão de Integração Nacional, Desenvolvimento Regional e da Amazônia (CINDRA) no desenho das políticas públicas para o desenvolvimento e integração da faixa de fronteira. Além disso, o I Programa Nacional de Desenvolvimento Regional (PNDR), de 2011, apresenta como áreas prioritárias o semiárido e a faixa de fronteira, esta devido à sua importância estratégica na promoção da integração (econômica) sulamericana (BRASIL, 2011b). "A Faixa de Fronteira é caracterizada pelos baixos indicadores sociais e por ser porta de entrada de diversos 'materiais' ilícitos; no entanto, a posição estratégica de seu território para a integração sul-americana e sua grande diversidade tornam-na especial para a PNDR II" (ALVES; ROCHA NETO, 2014, p. 325).

Em matéria de segurança, cabe mencionar o papel do Departamento da Política Federal (DPF), do Departamento da Política Rodoviária Federal (DPRF), das Polícias Estaduais (PEs), da Força Nacional de Segurança Pública e dos Gabinetes de Gestão Integrada de Fronteira (GGIF) na apreensão de armas de fogo e munições, de contrabandos e de drogas. No que se refere à questão social, cabe destacar a existência de transferências do Sistema Único de Saúde (SUS) para os municípios da faixa de fronteira (BRASIL, 2016). 
No contexto do Conselho Sul-Americano de Infraestrutura e Planejamento (COSIPLAN) e do Fundo para a Convergência Estrutural do MERCOSUL (FOCEM), é importante considerar a carteira de projetos associados à fronteira brasileira. Da mesma forma, do ponto de vista da política pública brasileira, o Plano Plurianual (PPA 2012-2015) desenvolve os seguintes programas: (i) Integração sul-americana: promoção o desenvolvimento socioeconômico e a integração das regiões inseridas na FF; (ii) Desenvolvimento Regional, Territorial Sustentável e Economia Solidária: criação 106.770 postos de trabalho nos Arranjos Produtivos Locais (APL) apoiados, sendo cerca de $20 \%$ na FF; (iii) Reforma Agrária e Ordenamento da Estrutura Fundiária: regularização e ratificação de 200 mil títulos de posses em faixa de fronteira; e (iv) Proteção e Promoção dos Direitos dos Povos Indígenas: estruturação de 5 unidades descentralizadas da Fundação Nacional do Índio (FUNAI), objetivando monitoramento territorial e proteção na FF com Peru, Colômbia e Venezuela (BRASIL, 2011a).

\section{Conclusões}

O presente artigo destacou as relações entre Integração Regional, Política Externa (Brasileira) e Políticas Públicas. Para tal, fez uma breve revisão da literatura sobre tais conceitos, destacando as mudanças e continuidades da PEB sobretudo a partir de 1990. Embora a integração regional tenha avançado desde então, é importante destacar a mudança de sua concepção, seja com o MERCOSUL, com a IIRSA ou mesmo com a UNASUL.

De toda forma, defende-se o esforço da PEB em assegurar a coesão do MERCOSUL, que instrumentalizou a integração regional como plataforma para a inserção internacional brasileira (VIGEVANI; RAMANZINI JR., 2011). Essa realidade, contudo, parece mudar sobretudo com a presença do atual presidente Temer, em especial com os direcionamentos apresentados pelo então ministro do MRE, José Serra.

Destacam-se as políticas públicas da Comissão Permanente para o Desenvolvimento e a Integração da Faixa de Fronteira (CDIF) voltadas para o aprofundamento da integração regional, evidenciando a necessidade de maior participação dos núcleos de fronteira na elaboração e condução dessas políticas. 
Essa mudança é fundamental para captar as particularidades das centenas de cidades localizadas em cada zona fronteiriça do Brasil.

Tal política é essencial, sobretudo para garantir a melhoria dos índices econômicos e sociais dessas cidades, historicamente piores que aqueles das demais regiões do Brasil. Para tal, é fundamental discutir prioridades, parcerias e fontes de financiamento para desenvolver projetos de educação, saúde, infraestrutura, trabalho e assistência social, por isso destaca-se não apenas o papel dos recursos nacionais, mas, principalmente, nas instâncias do MERCOSUL (FOCEM) e institucionais (COSIPLAN).

Portanto, defende-se maior compromisso das políticas públicas brasileira e dos países vizinhos para com governos subnacionais de fronteira, promovendo a participação sustentada das políticas de promoção da integração regional evitando, consequentemente, riscos e incertezas decorrentes da conjuntura doméstica e das influências externas. É necessário destacar que é nessas regiões onde mais 'se sente' a integração, que protagoniza o cotidiano dos cidadãos que lá habitam, por meio de interações transfronteiriças, com o próprio país (governos municipal, estadual e federal), com a sub-região e também com os países vizinhos (paradiplomacia).

\section{Referências bibliográficas}

A Paradiplomacia no Processo de Integração Regional: o caso do MERCOSUL. Revista Conjuntura Austral, v. 5, n. 21-22, pp. 103-123, Dez. 2013 - Mar. 2014, 2014.

AMORIM, Celso. Brazilian foreign policy under President Lula (2003-2010): an overview. Revista Brasileira de Política Internacional, v. 53 (special edition), pp. 214-240, 2010.

AMORIM NETO, Octavio; MALAMUD, Andrés. What Determines Foreign Policy in Latin America Systemic versus Domestic Factors in Argentina, Brazil, and Mexico, 1946-2008. Latin American Politics and Society, v. 57, n. 4, pp. 1-27, 2015.

BENTO, Fábio Régio. O papel das cidades gêmeas de fronteira na integração regional sul-americana. Revista Conjuntura Austral, v. 6, n. 27-28, pp. 50-53, dez. 2014-mar. 2015.

BLAVOUKOS, Spyros; BOURANTONIS, Dimitris. Identifying parameters of foreign policy change: An eclectic approach. Cooperation and Conflict, v. 49, n. 4, pp. 483-500, 2014. 
BOITO, Armando; BERRINGER, Tatiana. Social Classes, Neodevelopmentalism, and Brazilian Foreign Policy under Presidents Lula and Dilma. Latin American Perspectives, Issue 198, v. 41, n. 5, pp. 94-109, sep. 2014.

BORGES, Luís Maurício Martins. O Sentido da Integração da Política Pública do Brasil na América do Sul. Texto para Discussão, n. 1823, Ipea, Rio de Janeiro, 2013.

BORGES, Fábio. As relações do Brasil com os países sul-americanos nos governos de Fernando Henrique Cardoso e Lula (1995-2010): "hegemonia consensual" e seus limites. Monções: Revista de Relações Internacionais da UFGD, Dourados, v. 1, n. 2, pp. 96-117, jul./dez. 2012.

BRASIL. Segurança pública nas fronteiras, diagnóstico socioeconômico e demográfico: Estratégia Nacional de Segurança Pública nas Fronteiras (ENAFRON). NEVES, Alex Jorge das Neves; BAPTISTA, Gustavo Camilo; ENGEL, Cíntia Liara; MACHADO, Lia Osorio (Org.). Brasilia: Ministério da Justiça e Cidadania, 2016.

Portaria $n^{\circ}$ 125, de 21 de março de 2014. Estabelece o conceito de cidades-gêmeas nacionais, os critérios adotados para essa definição e lista todas as cidades brasileiras por estado que se enquadram nesta condição. Diário Oficial da União (DOU), Brasilia, DF, 24 mar. 2014, Seção 1, p. 45.

. Ações e políticas públicas para o desenvolvimento e integração da Faixa de Fronteira. Apresentação da Ministra Carla Barroso Carneiro, Divisão da América Meridional IV. Brasília: Ministério das Relações Exteriores, jul. 2013a.

Políticas Públicas para o Desenvolvimento e Integração da Faixa de Fronteira. Apresentação de Alexandre Peixoto, Secretaria de Desenvolvimento Regional. Brasília: Ministério da Integração Nacional, jul. 2013b.

Plano Plurianual 2012-2015: projeto de lei. Brasília: MP, 2011a.

Política Nacional de Desenvolvimento Regional - PNDR. Sumário executivo. Brasília: Ministério da Intearacão Nacional, $2011 \mathrm{~b}$.

Decreto de 8 de setembro de 2010. Institui a Comissão Permanente para o Desenvolvimento e a Integração da Faixa de Fronteira - CDIF. Brasília, DF, 8 set. 2010.

Faixa de Fronteira: Programa de Promoção da Faixa de Fronteira PDFF. Brasília: Ministério da Integração Nacional, 2009.

. Proposta de Reestruturação do Programa de Desenvolvimento da Faixa de Fronteira: bases de uma política integrada de desenvolvimento regional para a faixa de fronteira. Brasília: Ministério da Integração Nacional, 2005.

BRESSAN, Regiane Nitsch. Elites políticas, integração regional e política externa. Revista Estudos Políticos, v. 6, n. 1, pp. 228-253, dez. 2015.

BUENO, Clodoaldo; VIGEVANI, Tullo; RAMANZINI JR., Haroldo. Latin American Integration: A Brazilian View. In: RIVAROLA PUNTIGLIANO, Andrés; BRICEÑO RUIZ, José (Orgs.). Resilience of regionalism in Latin America and the Caribbean: development and autonomy. New York, NY: Palgrave Macmillan, pp. 207-231, 2013.

BÜHRING, Marcia Andrea. (Re)Definição de Fronteira(s) e Cidades Gêmeas Brasil e Uruguai. Revista de Direito de Família e Sucessão, v. 1, n. 2, pp. 230260, jul/dez 2015.

CAMARGO, Sonia de. Mercosul: crise de crescimento ou crise terminal? Lua Nova: Revista de Cultura e Política, n. 68, pp. 57-90, 2006. 
CARRANZA, Mario E. Resilient or Declining Latin American Regional Economic Blocs in the Postneoliberal Era. American Politics and Society, v. 56, n. 3, pp. 163-172, 2014.

. Can Mercosur Survive Domestic and International Constraints on Mercosur? Latin American Politics and Society, v. 45, n. 2, pp. 67-103, 2003. CASON, Jeffrey; POWER, Timothy. Presidentialization, Pluralization, and the Rollback of Itamaraty: Explaining Change in Brazilian Foreign Policy Making in the Cardoso-Lula Era. International Political Science Review, v. 30, n. 2, pp. 117140, mar. 2009.

CASTELO BRANCO, Álvaro Chagas. A paradiplomacia como forma de inserção internacional de unidades subnacionais. Prismas: Direito, Políticas Públicas e Mundialização, Brasilia, v.4, n, 1, pp. 48-67, jan/jul. 2007.

CERVO, Amado Luiz. Relações internacionais do Brasil: um balanço da era FHC. Revista Brasileira de Política Internacional, v. 45, n. 1, pp. 5-35, 2002.

DABĖNE, Olivier. The Politics of Regional Integration in Latin America: Theoretical and Comparative Explorations. New York: Palgrave Macmillan, 2009. ESPÓSITO NETO, Tomaz. O Tortuoso Caminho da Cooperação entre Brasil e Argentina: de Itaipu ao MERCOSUL. Revista Conjuntura Austral, v. 4, n. 17, pp. 70-96, Abr./Mai. 2013

HONÓRIO, Karen dos Santos. O paradoxo do regionalismo à brasileira (20002010): notas para se pensar a ação do Brasil na integração da América do Sul através da participação da IIRSA. Monções: Revista de Relações Internacionais da UFGD, Dourados, v. 2, n. 3, pp. 166-205, jan./jun. 2013.

HVEERN, Helge. Integration by Whom, for Whom, against Whom? On the relationship between neo-classical integration theory, processes of integration, and social structure. Cooperation and Conflict, IX, pp. 263-284, 1974.

KRAPHOL, Sebastian; MEISSNER, Katharina; MUNTSCHICK, Johannes. Regional Powers as Leaders or Rambos? The Ambivalent Behaviour of Brazil and South Africa in Regional Economic Integration. Journal of Common Market Studies, v. 52, n. 4. pp. 879-895, 2014.

LASWELL, Harold D. Politics: Who Gets What, When, How. Cleveland, Meridian Books. 1936/1958.

LINDBLOM, Charles E. The Science of Muddling Through. Public Administration Review 19, pp. 78-88, 1959.

Still Muddling, Not Yet Through. Public Administation Review 39, pp. 517-526, 1979.

LUSTIG, Carola M. Soft or Hard Power? Discourse Patterns in Brazil's Foreign Policy toward South America. Latin American Politics and Society, v. 58, n. 4, pp. 103-125, 2016.

MALAMUD, Andrés. A Leader without Followers? The Growing Divergence between the Regional and Global Performance of Brazilian Foreign Policy. Latin American Politics and Society, v. 53, n. 3, pp. 1-24, 2011.

MARIANO, Marcelo Passini; RAMANZINI JR., Haroldo. Structural Limitations of the Mercosur: An Analysis Based on the Brazilian Foreign Policy Positions. The Latin Americanist, v. 56, pp. 161-180, 2012.

MATTLI, Walter. The Logic of Regional Integration: Europe and Beyond. Cambridge: Cambridge University Press, 1999.

MERCOSUL. Mercosul/CMC/DEC o 41/04. Decisão que cria o Foro Consultivo de Municípios, Estados Federados, Províncias e Departamentos do Mercosul, 
2004. Disponível em: http://www4.planalto.gov.br/saf-fccr/fccrmercosul/estrutura/decisao-no-41-04-do-conselho-mercado-

comum?portal_status_message=Changes\%20saved. Acessado em: 18 de junho de 2017.

MILANI, Carlos R. S.; PINHEIRO, Leticia. Política Externa Brasileira: Os Desafios de sua Caracterização como Política Pública. Contexto Internacional, v. 35, n. 1, pp. 11-41, jan/jun 2013.

MITRANY, David. The functional approach to world organization. International Affairs, v. 24, n. 3, pp.350-363, 1948.

NYE, Joseph S. Comparative Regional Integration: Concept and Measurement. International Organization, v. 22, n. 4, pp. 855-880, Aut. 1968.

ONUKI, Janina; OLIVEIRA, Amâncio Jorge de. Eleições, Política Externa e Integração Regional. Revista de Sociologia e Política, v. 27, pp. 145-155, nov. 2006.

PECEQUILO, Cristina Soreanu. A política externa do Brasil no século XXI: os eixos combinados de cooperação horizontal e vertical. Revista Brasileira de Política Internacional, v. 51, n. 2, pp. 136-56, 2008.

PECEQUILO, Cristina Soreanu; CARMO, Corival Alves do. Regional Integration Aad Brazilian Foreign Policy: Strategies in the South American space. Revista de Sociologia e Política, v. 21, n. 48, pp. 51-65, dez. 2013.

PÊGO, Bolívar; MOURA, Rosa; KRÜGER, Caroline; NUNES, Maria; OLIVEIRA, Samara. Fronteiras do Brasil: diagnóstico e agenda de pesquisa para política pública. Brasília: Ipea/Ml, volume 2, 2017.

PENHA, Bruna; DESIDERÁ NETO, Walter Antonio; MORAES, Rodrigo Fracalossi de. O Mercosul e as Regiões de Fronteira. Rio de Janeiro: Ipea, 2017. PIMENTA NETO, Marcílio Diniz. Faixa de Fronteira e o Domínio Público: Um estudo sobre a faixa de fronteira face o domínio público e o direito à propriedade. Jusbrasil, 2014. Disponível em: https://marcilioberserk.jusbrasil.com.br/artigos/169553071/faixa-de-fronteira-eo-dominio-publico. Acesso em: 23/11/2017.

PINHEIRO, Leticia. Autores y actores de la política exterior brasileña. Foreign Affairs Latinoamérica, v. 9, n. 2, pp. 14-24, 2009.

PRADO, Henrique Sartori de Almeida. Inserção dos atores subnacionais no processo de integração regional: o caso do Mercosul. Dourados-MS: Ed. UFGD, 2013.

A cooperação descentralizada e transfronteiriça no MERCOSUL: a construção de um regime simbólico. In: ESPÓSITO NETO, Tomaz; ALMEIDA PRADO, Henrique Sartori de. Fronteiras e relações internacionais. Curitiba: Íthala, pp. 55-82, 2015.

PUTNAM, Robert. Diplomacy and domestic politics: the logic of two-level games. International Organization, v. 42, n. 3, pp. 427-460, 1988.

1976.

. The Comparative Study of Political Elites. New Jersey: Prentice Hall,

RICHARD, Yann. Intéaration réqionale, régionalisation, régionalisme - Les mots et les choses. Confins, n. 20, 2014.

ROSAMOND, Ben. Theories of European Integration. Basingstoke: Macmillan 2000. 
ROSENAU, James N. Towards the study of national-international linkages. In: ROSENAU, James N. (ed.). Linkage Politics. New York: Free Press, pp. 339380, 1969.

SANTOS, Thauan; DINZ JÚNIOR, Carlos Antônio. MERCOSUL e Políticas Educacionais: a educação como vetor de promoção da integração regional. II Encontro de Economia Política Internacional - II ENEPI, UFRJ, 2017.

SARAIVA, Miriam. Brazilian Foreign Policy Towards South America During the Lula Administration: Caught between South America and Mercosur. Revista Brasileira de Política Internacional, v. 53 (special edition), pp. 151-168, 2010.

SIMON, Herbert. Comportamento Administrativo. Rio de Janeiro: USAID. 1957. SNYDER, Robert S. Bridging the realist/constructivist divide: the case of the counterrevolution in Soviet foreign policy at the end of the cold war. Foreign Policy Analysis, v. 1, n. 1, pp. 55-71, 2005.

SOARES DE LIMA, Maria Regina. Instituições Democráticas e Política Exterior. Contexto Internacional, v. 22, n. 2, pp. 265-303, 2000.

SOARES DE LIMA, Maria Regina; HIRST, Mónica. Brazil as an Intermediate State and Regional Power: Action, Choice and Responsibilities. International Affairs, v. 82, n. 1, pp. 21-40, 2006.

SOLDATOS, Panayotis. An Explanatory Framework for the study of Federated States as Foreign Policy Actors. In: MICHELMANN, Hans J.; SOLDATOS, Panayotis. Federalism and international relations: the role of subnational units. Oxford: Clarendon Press, pp. $34-53,1990$.

SPEKTOR, Matías. El regionalismo de Brasil. In: SORJ, Bernardo; FAUSTO, Sergio (Eds.) Brasil y América del Sur: miradas cruzadas. Buenos Aires: Catálogos, pp. 161-98, 2011.

VAZ, Alcides Costa. Brazilian Foreign Policy Under Lula: Change or Continuity? Friedrich-Ebert-Stiftung Briefing Paper, 2004.

VIGEVANI, Tullo. As dificuldades de fundo do Mercosul. Boletim Meridiano 47, v. 13, n. 134, pp. 28-31, nov-dez 2012.

VIGENAVI, Tullo; RAMANZINI JR., Haroldo. The Impact of Domestic Politics and International Changes on the Brazilian Perception of Regional Integration. Latin American Politics and Society, v. 53, n. 1, pp. 125-155, 2011.

VIGEVANI, Tullo; RAMAZINI JR., Haroldo; FAVARON, Gustavo; CORREIA, Rodrigo A. O papel da integração regional para o Brasil: universalismo, soberania e percepção das elites. Revista Brasileira de Política Internacional, v. 51, n.1, pp. 5-27, 2008.

VIGEVANI, Tullo; WANDERLEY, Luiz Eduardo W.; BARRETO, Maria Inês; MARIANO, Marcelo Passini (Orgs.) A Dimensão subnacional e as Relações Internacionais. São Paulo: Ed.UNESP; EDUC, 2004.

Recebido em 19 de junho de 2017. Aprovado em 02 de outubro de 2017. 